\title{
Groundwater quality assessment of Dashtestan using WQI index in 2007
}

\author{
Omid Memarian Sorkhabi \\ (omidmemaryan@gmail.com)
}

Department of Geomatics Engineering, Faculty of Civil Engineering and Transportation, University of Isfahan, Isfahan, Iran.

\begin{abstract}
Water is a major source of economic development, social security and poverty reduction. The value of this resource on the one hand and its limitation on the other hand has led to increased management measures to maintain the quantity and quality of water by different communities. In this research, the water quality index (WQI) for the Dehroud and Tang Eram regions of Dashtestan in 2007 has been investigated. The average WQI in 2007 is 66,798. WQI was better off in the Northeast in 2007 than in the Southeast. The maximum values of PH, TDS and EC in 2007 are 7.9, 5000 and 7500 , respectively.
\end{abstract}

Keywords: WQI, water, groundwater, Dehroud region, Dashtestan

\section{Introduction}

Water is a major source of economic development, social security and poverty reduction. The value of this resource on the one hand and its limitation on the other hand has led to increased management measures to maintain the quantity and quality of water by different communities. Environmental changes and human activities affect the quantity and quality of water [1]. Although groundwater is the most abundant available source of fresh water in the world, which accounts for $97 \%$ of the world's freshwater resources except polar ice and glaciers, and is sometimes called hidden wealth, its existence and importance are not well understood [2]. As a result, the necessary measures to identify water conservation and management of environmentally sustainable methods are either not done or are done too late [3-5]. Approximately $85 \%$ of the area of Iran is covered by areas with the arid and semiarid climate that are completely dependent on groundwater resources and due to lack 
of appropriate spatial-temporal distribution of rainfall water source has no alternative to meet their water needs [5-10].

Eram section is one of the sections of Dashtestan city in Bushehr province in the south of the country to the center of Tang Eram city. Most of the plains of this region are critical. Therefore, it is necessary to study the quality and protection of groundwater. In this research, WQI for the Dehroud and Tang Eram in 2007 has been investigated.

\section{Results}

PH, TDS and EC measurements have been studied in this research in 2007. Figure 1 shows the PH, TDS, and EC for 2007. According to the results, the maximum values of PH, TDS and EC in 2007 are 7.9, 5000 and 7500, respectively.
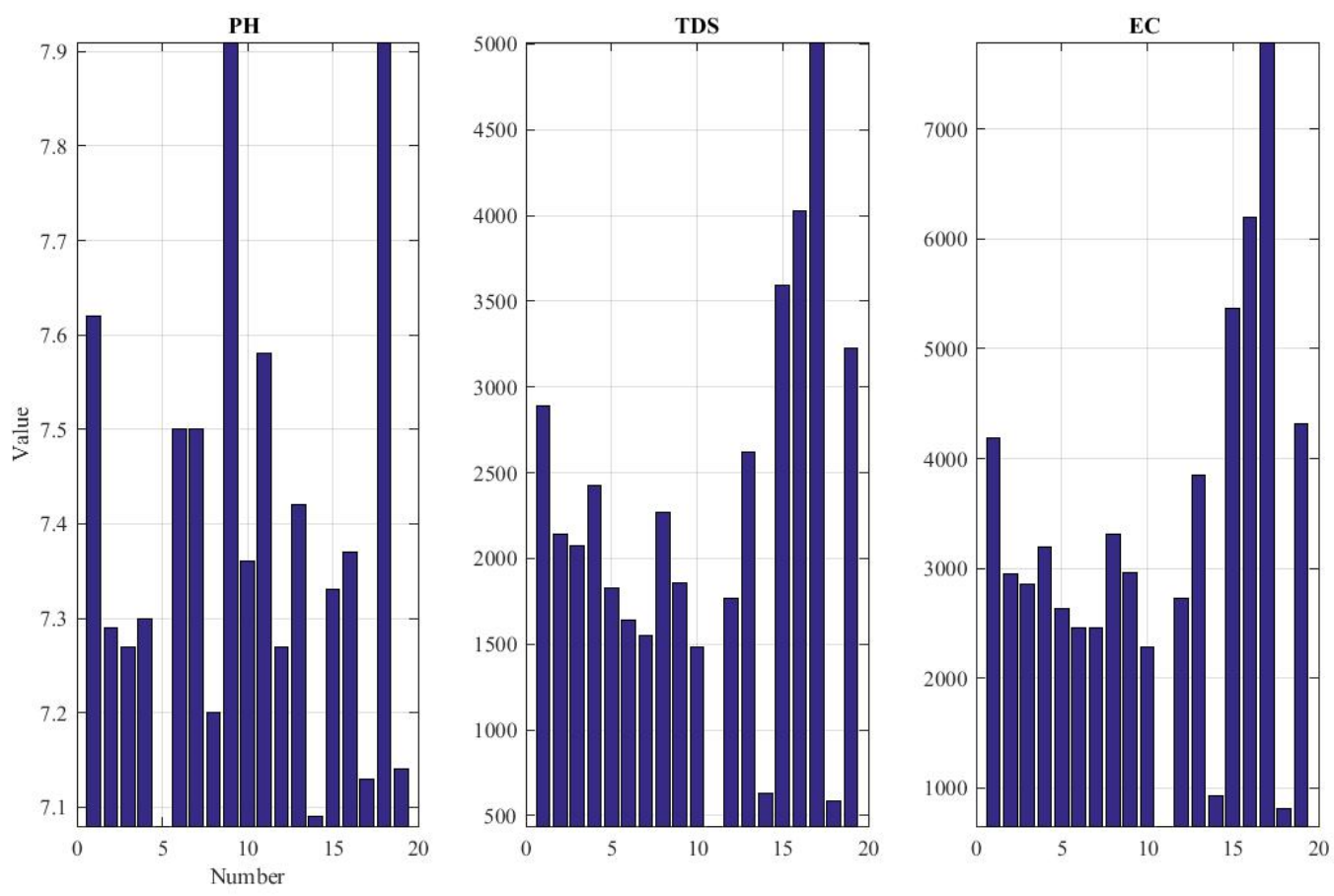

Figure 1 Diagrams of PH, TDS and EC in 2007

Figure 2 shows the WQI in 2007. According to the results, the average WQI in 2007 is $66,798$. 


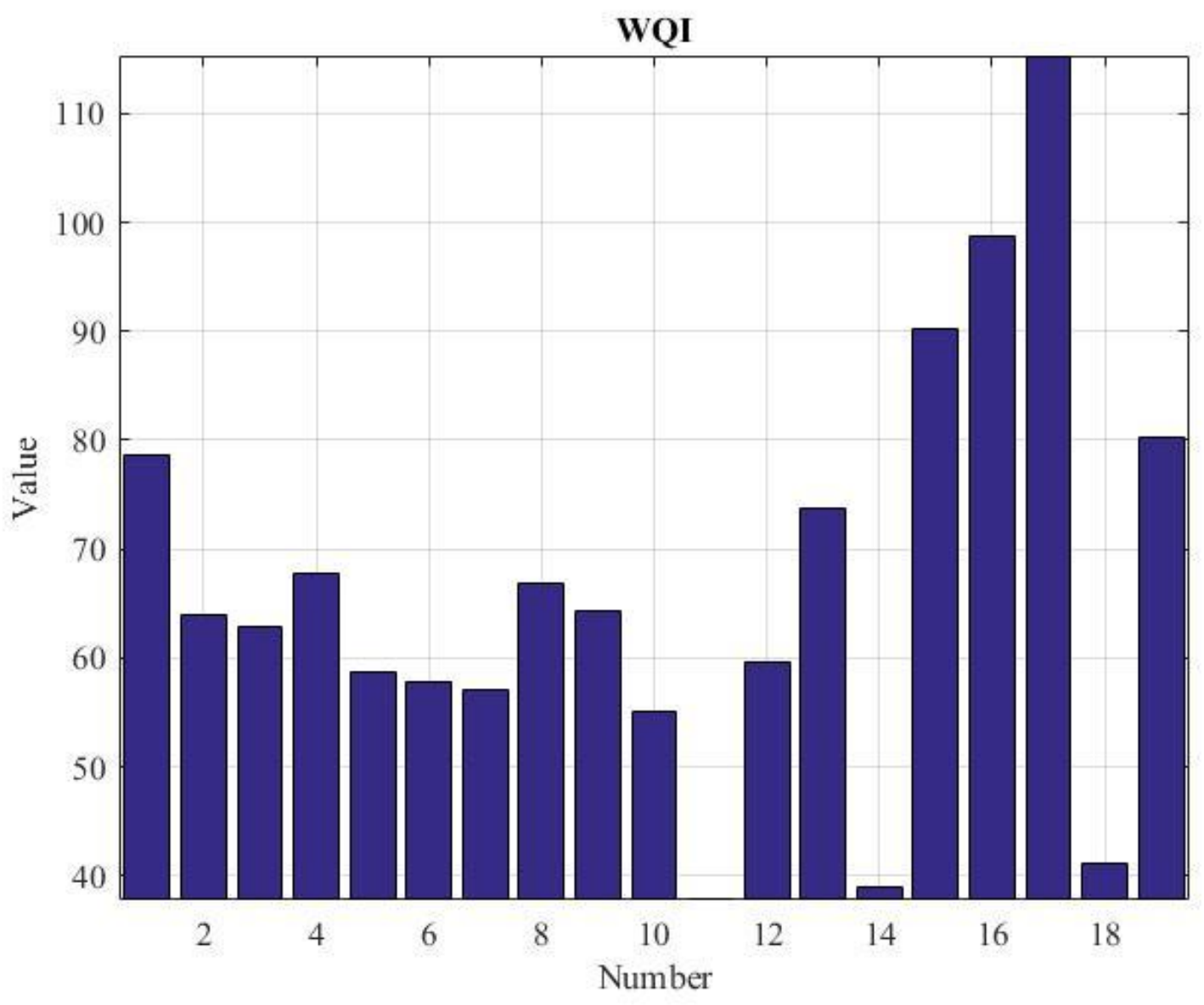

Figure 2 WQI in 2007

Figure 3 shows the WQI in 2007. WQI was better off in the Northeast in 2007 than in the Southeast. 


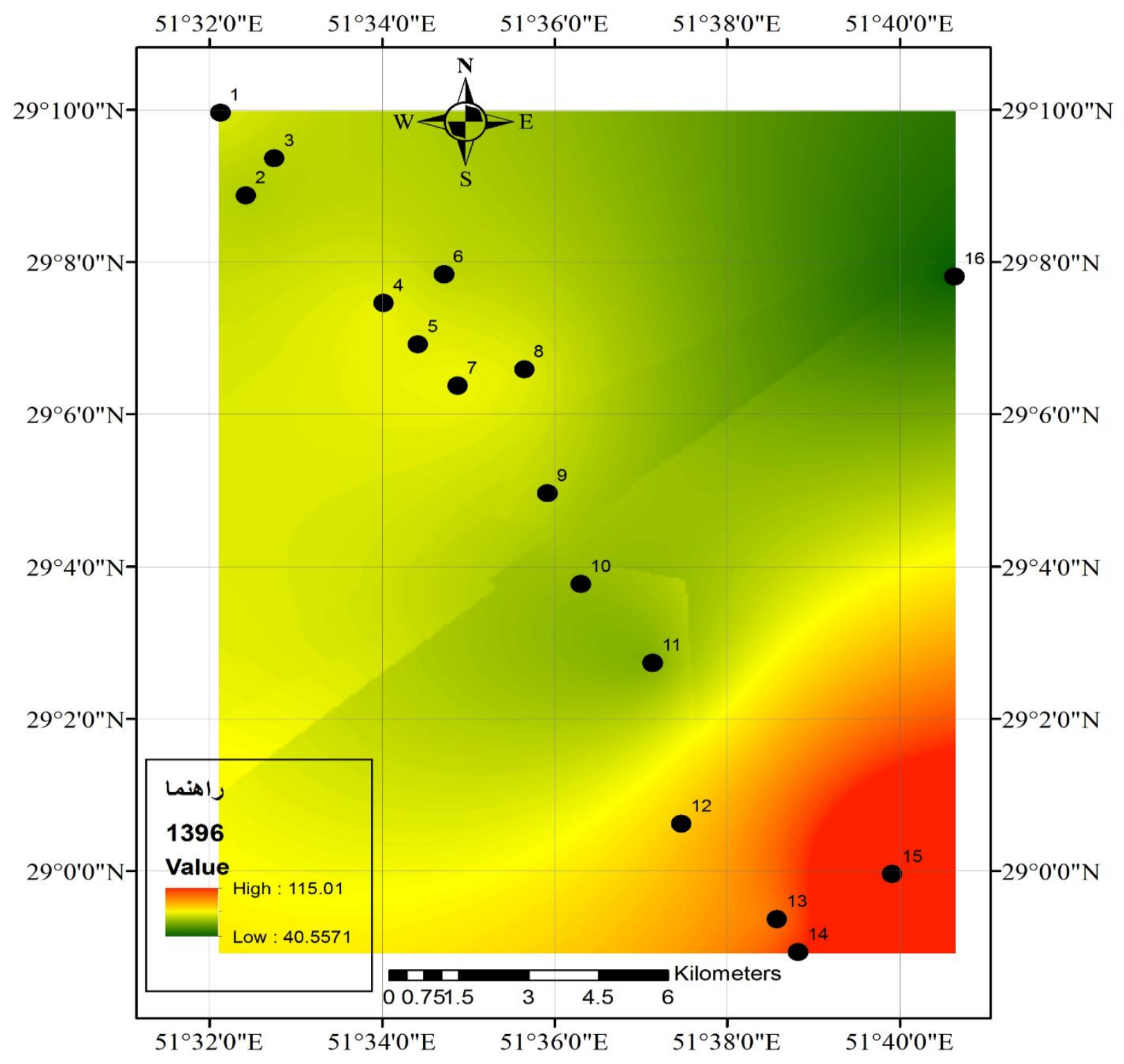

Figure 3 WQI in 2007

\section{Conclusion}

In this research, WQI for the Dehroud and Tang Eram in 2007 has been investigated. According to the results, the average WQI in 2007 is 66,798. WQI was better off in the Northeast in 2007 than in the Southeast. The maximum values of PH, TDS and EC in 2007 are 7.9, 5000 and 7500, respectively. For future research, deep learning and satellite measurements can be used to estimate WQI $[3,11]$. 


\section{Competing interests:}

The authors declare no competing interests.

\section{References}

[1] Uddin MG, Nash S, Olbert AI. A review of water quality index models and their use for assessing surface water quality. Ecological Indicators. 2021 Mar 1;122:107218.

[2] Adimalla N. Application of the Entropy Weighted Water Quality Index (EWQI) and the Pollution Index of Groundwater (PIG) to Assess Groundwater Quality for Drinking Purposes: A Case Study in a Rural Area of Telangana State, India. Archives of Environmental Contamination and Toxicology. 2021:1-0.

[3] Memarian Sorkhabi O, Asgari J, Amiri-Simkooei A. Wavelet decomposition and deep learning of altimetry waveform retracking for Lake Urmia water level survey. Marine Georesources \& Geotechnology. 2021 Mar 10:1-1

[4] Memarian Sorkhabi O. Geoid determination based on log sigmoid function of artificial neural networks:(a case study: Iran). Journal of Artificial Intelligence in Electrical Engineering. 2015 Mar 1;3(12):18-24.

[5] Sorkhabia OM, DJAMOUR Y. Wavelet Transform Analysis of Ionospheric Electron Content Changes before Large Earthquakes. Journal of Geomatics Science and Technology, 2015.

[6] Sorkhabi OM, Naderi A, Emadi R. Terrain Effect on Geoid Determination Case Study: NW Iran. Journal of Geomatics Science and Technology. 2014 Nov 10;4(2):139-48.

[7] Sorkhabi OM. Deep learning of dynamic sea-level variability to investigate the relationship with the floods in Gothenburg. 2021. DOI: 10.21203/rs.3.rs-422515/v1

[8] Memarian Sorkhabi O, Asgari J, Amiri-Simkooei A. Monitoring of Caspian Sea-level changes using deep learning-based 3D reconstruction of GRACE signal. Measurement. 2021 Apr 1;174:109004.

[9] Sorkhabia OM, Asgaria J, Amiri-Simkooeia A. Caspian Sea Level Survey with GRACE and GRACE-FO. 2020.

[10] Memarian Sorkhabi O, Djamour Y. Estimation of Geodetic Virtual Velocity Based On Back Propagation Artificial Neural Networks (Case Study: NW Iran). Journal of Geoscience. 2015 Jun 1;24(95):69-76.

[11] Memarian Sorkhabi O, Asgari J, Amiri Simkooei A. Analysis of Greenland mass changes based on GRACE four-dimensional wavelet decomposition. Remote Sensing Letters. 2021 May 4;12(5):499-509. 